\title{
Mould fabrication for polymer optics
}

\section{Speich \\ marco.speich@htw-aalen.de}

R. Börret
Aalen University, Centre for optical technologies, Aalen, 73430, Germany

Aalen University, Centre for optical technologies, Aalen, 73430, Germany

This work is focused on the process chain for mould fabrication for the injection moulding of optical components. To achieve a good form and surface quality on steel moulds is the intention; the new process chain should consist of just 3 steps instead of 5; nickel plating and diamond turning are superseded. Manual polishing is replaced by robot polishing. [DOI: http://dx.doi.org/10.2971/je0s.2011.11050]

Keywords: steel polishing, mould fabrication, polymer optics, robot polishing

\section{INTRODUCTION}

Plastic injection moulding is a commonly used process for the production of plastic parts in large numbers [1]. A particular kind of plastic injection moulding is the production of plastic optics. As optical design engineers discover the many ways that plastic optics can manage light, applications for the devices continue to grow. Plastic optical elements and systems appear in a wide spectrum of commercial, military and medical applications, including surgical instruments. Other examples include imaging systems for displays, night-vision goggles and various kinds of head-mounted displays. Plastic optics are frequently found in PC peripherals, such as videoconferencing cameras and microscopes and in consumer devices such as compact disc and DVD players [2]. The quality of the moulded parts is directly dependent on the surface quality of the mould.

The topic of this work arose out of a research project with UVEX safety group. UVEX, a producer of safety goggles, is also using injection moulding of plastic optics. Moulds are of different sizes and the radius of curvature also varies. UVEX also uses this process to produce plastic visors for helmets. So there is need of spherical as well as of cylindrical moulds. Another problem is that wearers or workers who are supposed to wear the safety goggles often criticize the image quality of the goggles. Figure 1 shows a barcode seen through goggles in accordance to DIN standards [3].

In general, moulds for plastic injection moulding are polished by manual workers $[4,5]$. To achieve good results concerning surface roughness and shape deviation the workers have to be experts in polishing. Above all the need a lot of time to finish a single mould and this makes the production of moulds very expensive. Experts have two different ways of polishing moulds. One method is extensive polishing with large tools. This method just works for spherical moulds. Depending on

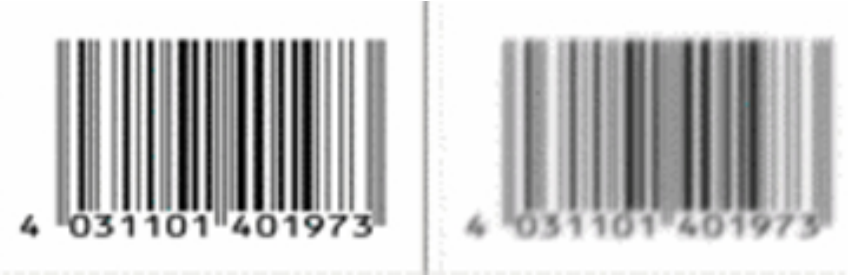

FIG. 1 left: image definition without safety glasses, right: image definition with safety glasses, DIN EN 166 conform (simulation)

the initial state of the mould and the specifications, different tool materials are inevitable and up to 8 tools are needed to lap and polish one spherical mould in specifications. Different tools are used for each state of the sample and for different grain sizes of the polishing powder. To avoid that big number of tools, some experts use polishing pitch for extensive polishing but the preparation of the pitch tools is inconvenient, not easy and the process is dirty. For that reason a lot of optic producers dont want this pitch polishing process in their companies.

The other method to polish steel moulds for plastic injection moulding is local manual polishing. Polishing experts are using small sub aperture tools of different materials and move these tools over the surface by hand. This method leads to a good surface roughness but it is very hard to control the shape deviation. There are moulds that can be polished by special workers only because they are using the best fitting combination of tool, polishing agent and feeling for this type of steel.

\section{Aims of the research}

One target of this work is to create a new process chain for the manufacturing of steel moulds for injection moulding. Expensive steps in the process chain (Figure 2) should be 


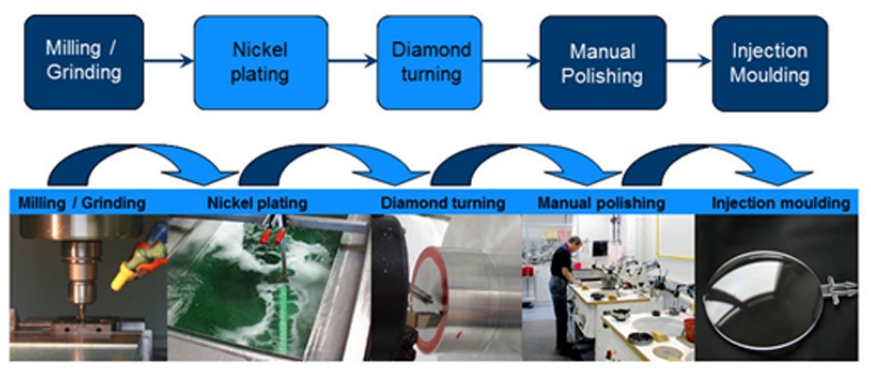

FIG. 2 Existing process chain for mould production [6]-[8]

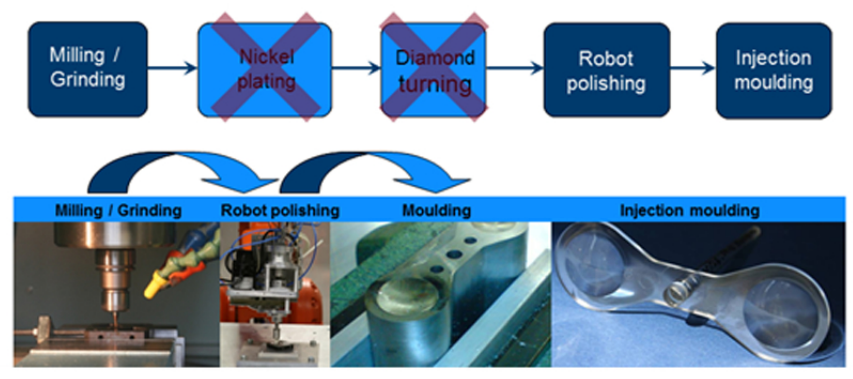

FIG. 3 New process chain for mould production

replaced by less and cheaper steps. The new process chain (Figure 3) should not only be cheaper but also easier to handle and more stable than the existing one.

Diamond turning itself is a very expensive process step because of the required diamond turning equipment. Apart from that the steel mould has to be nickel plated prior to the diamond turning. The nickel plating can lead to lifetime issues concerning the mould. After some 10.000 shots the surface can get cracks and the mould has to be reworked. To replace the nickel plating could mean extensive economies. There are attempts to bypass the nickel plating for example by thermochemical surface zone treatment [9]. But the common way is nickel plating.

Manual polishing is also a very unstable process. This process is, as mentioned above, very dependent on the worker and expensive due to the need of specialists and a big number of tools. Therefore this is the $3^{\text {rd }}$ step that will be removed with the new process chain.

In the new process chain the 3 steps mentioned above are substituted with one new step, robot polishing. Several small tools for the robot polishing process are necessary to achieve good surface results starting from a ground surface but the process should be very stable and easy to handle. The robot step also contains robot lapping prior to polishing. This is necessary when starting from a ground surface $[10,11]$.

\section{Process Development}

To make the new process chain working for all kind of steel moulds for plastic injection moulding it was necessary to develop a stable, easy to handle process. There are some

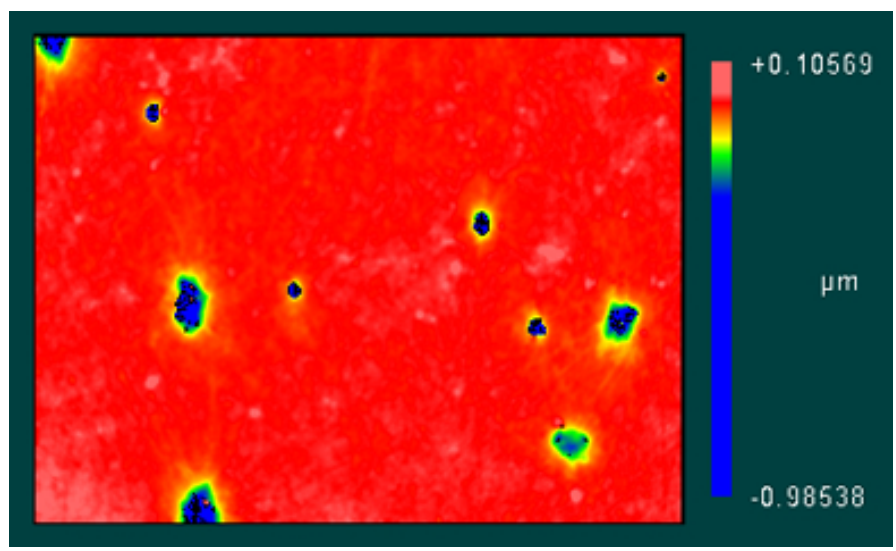

FIG. 4 Pitting on the polished steel surface

important factors concerning the process. Experiments were completed with different tool materials for the polishing / lapping tool, different steel types of the mould, several types of diamond powder and various grain sizes as well as varying relative speed and different contact pressures between tool and mould.

To achieve fast results in the process development stage, first experiments were realized with areal, extensive polishing. Big plane polishing tools of different materials and smaller steel samples, also plane and hardened to approx. $60 \mathrm{HRC}$ (Rockwell C hardness) were produced for first attempts [12]-[14].

Starting with cheap, edgeless diamond powder led to holes, pores and pitting on the surface. Pitting is an undesirable defect; carbides are pulled-out of the steel matrix by diamond grain [15]. This is probably because the monocrystalline diamond powder and the natural diamond powder are to edgeless or the polishing tool is too soft.

Tests with different types of diamond powder showed that the only diamond powder leading to good results on hardened steel samples is powder of polycrystalline synthetic diamond. Polycrystalline diamonds are made of sintered nanodiamond particles that were produced in the so called detonation synthesis process [16]-[18].

Different tool materials have been investigated for the different process steps. First lapping was done with a hard metal tool and diamond powder of big grain size. Fine lapping with softer metal tools and smaller diamond grain size led to already good roughness values. Surface finishing was then performed with a plastic tool.

With the latest results of process development the surface roughness almost met the requirements. Starting from a ground sample with a surface roughness of about $800 \mathrm{~nm}$ and a PV value of $7.3 \mu \mathrm{m}$ the polishing step led to a surface roughness of $8.8 \mathrm{~nm}$ and a PV value of $83.2 \mathrm{~nm}$. Figure 5 and Figure 6 show a micro interferometer measurement of the initial surface and the polished surface, the field of view in 


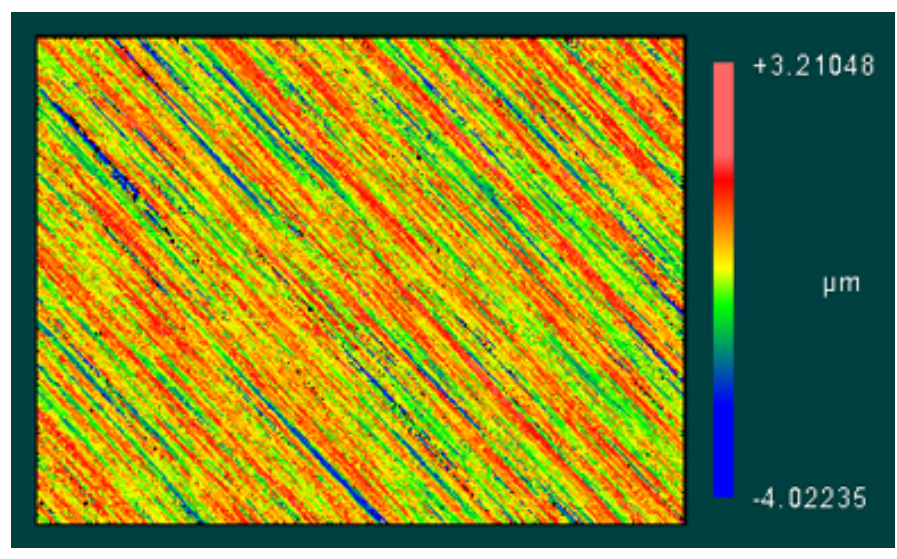

FIG. 5 Initial, ground surface; PV $7.3 \mu \mathrm{m}$, roughness rms $800 \mathrm{~nm}$

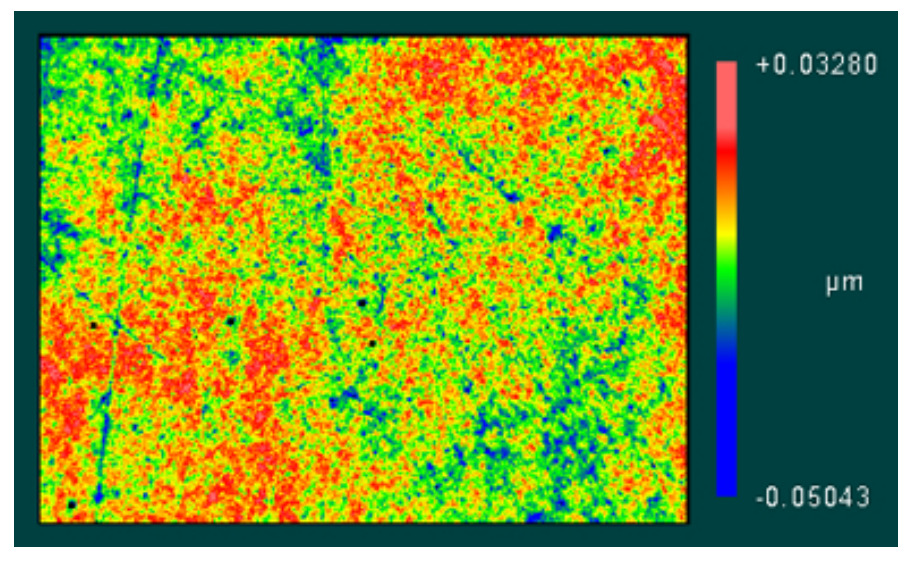

FIG. 6 Polished surface; PV $83.2 \mathrm{~nm}$, roughness rms $8.8 \mathrm{~nm}$

both Figures is $4.94 \times 3.70 \mathrm{~mm}$.

The rms values for the surface roughness after different process steps can be seen in Figure 7. The roughness is considerably approved from step to step.

\section{Preston-Coefficient}

Grinding is a very common method to achieve good surfaces with high rates of material removal [19]. The new process chain starts with a ground sample and with hard tools. For the first step a diamond powder with a big grain size was chosen. This rough process is to remove the clearly visible grinding marks (as can be seen in Figure 5). These grinding

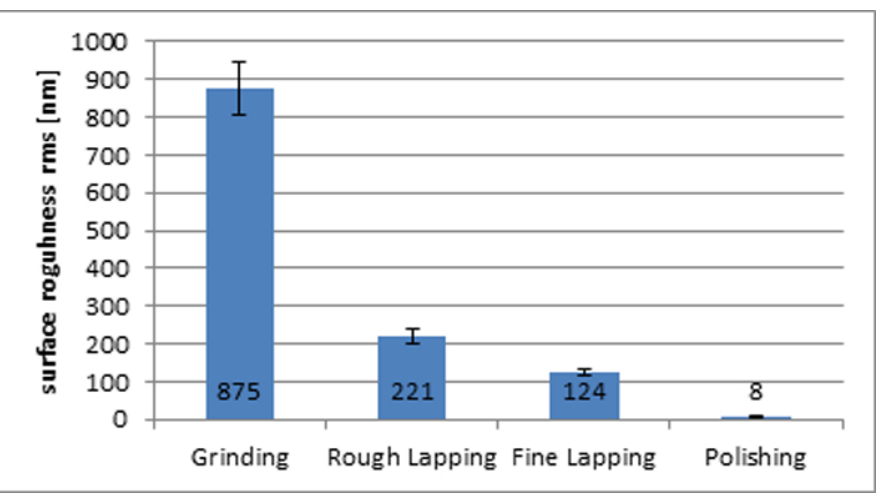

FIG. 7 Surface roughness (rms) after different process steps in $\mathrm{nm}$

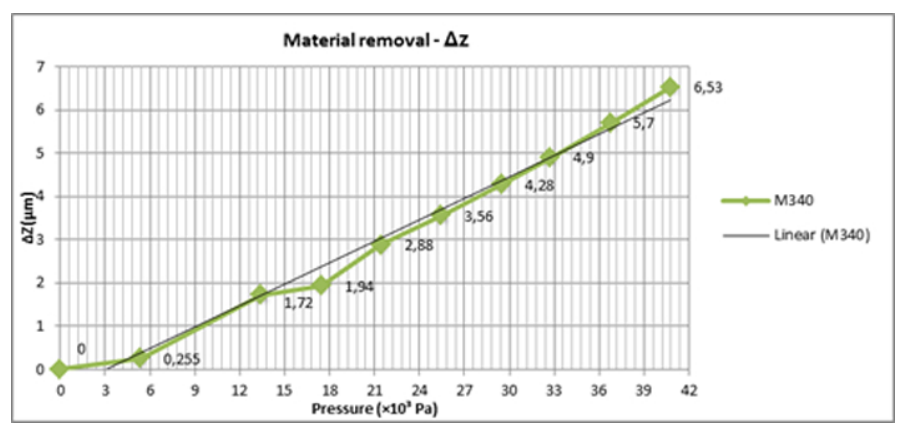

FIG. 8 Material removal over contact pressure for steel type M340

marks are typically between 6 to $15 \mu \mathrm{m}$ high.

Preston stated an equation in 1927 which describes the material removal over time dependent on relative speed, contact pressure and a coefficient called Preston coefficient [20].

$$
\frac{\Delta z}{\Delta t}=k \times v \times P
$$

This coefficient comprises tool material, polishing agent, sample material and ambient conditions. So if this coefficient is known the process time can be chosen fitting to the structures that have to be removed.

Several experiments with varying contact pressures were run to determine the Preston coefficient. Steel samples were prepared prior to the experiments and a second surface was generated on the sample; the new lower surface can be used as a reference and the upper surface for lapping experiments. After every process step the total material removal was measured with a CNC-controlled, high-precision measuring machine from ZEISS [21] .

The graph behaves almost linear so the Preston equation was solved with the slope of the best fitted linear to the graph (Figure 8).

This leads to a Preston coefficient of $7.59 \times 10^{-13} \mathrm{~Pa}^{-1}$ for the combination of hardened steel sample, cast iron lapping tool and diamond suspension.

\section{Outlook}

Process development led to a stable process that can be handled easily. Different parameters have been evaluated and perfect parameters were found. With these ideal parameters different users could produce surfaces free from errors like pitting or holes.

The gained knowledge from extensive polishing should be adapted to local polishing. Local polishing means, small tools and a special polishing robot head with a motor. The robot moves the rotating tool over the surface, this has the advantage that the process is not only limited to rotation 


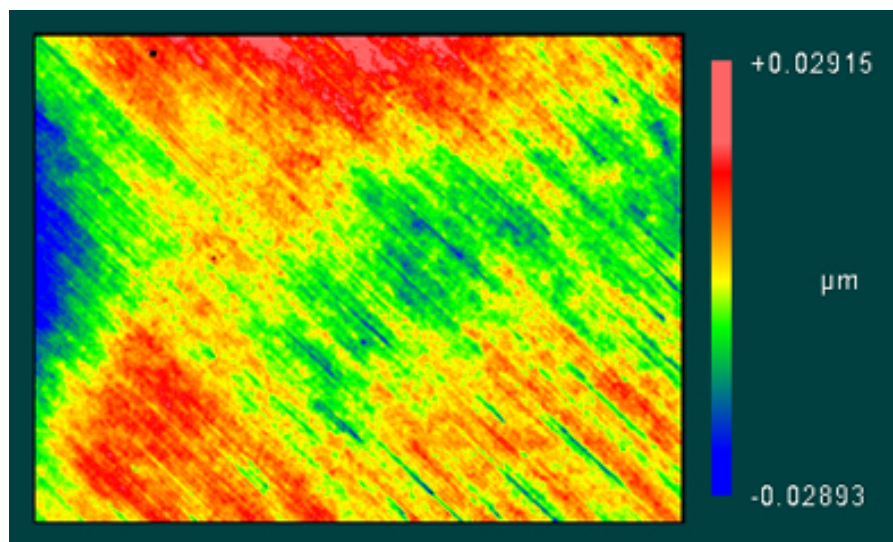

FIG. 9 Results after local robot polishing with a small tool

symmetrical surfaces. But this process is even harder to handle because polishing is a time controlled process, not a travel controlled process like common cad-cam processes.

Zaphod, a proprietary developed software from Aalen University helps to generate time controlled codes for the robot control. But the transfer from extensive polishing to local polishing will need some more efforts to be done.

Measurement result of the current local polishing process can be seen in Figure 9. The roughness value of this surface is $7.4 \mathrm{~nm}$ rms. Further experiments should result in even better surfaces.

UVEX provides moulds for first polishing experiments of the new local polishing process on curved surfaces. Moulds that lead to good polymer parts have an approximate roughness rms of $5 \mathrm{~nm}$ and there are no visible defects or structures on the surface. If the robot polished mould fits these requirements first injection moulding test will be performed.

\section{Acknowledgments}

The authors would like to thank the Bavarian Research Foundation for funding IVOS research project.

\section{References}

[1] E. Hering, and R. Martin, "Fertigung optischer Komponenten und Systeme (Manufacturing of optical components and systems", in Photonik - Grundlagen, Technologie und Anwendung (Photonics Basics, technology and application), p. 105-128 (Springer, Berlin, 2005).

[2] Beich, W.S., "Plastic Optics - Specifying Injection-Molded Plastic Optics". Photonics Spectra, 2002. 36(3): p. 127-132.

[3] Börret, R., D. Nagengast, and A. Langenbucher, Research proposal for IVOS research project, 2009.

[4] C. Brecher, et al., "Development of a force controlled orbital polishing head for free form surface finishing" Prod. Engineer. 4(2-3), 269-277 (2010)
[5] R. Börret, et al., "Minimized process chain for polymer optics" in Proceedings of SPIE 2008, p. 706118-706118-8, (Novel Optical Systems Design and Optimization $\mathrm{XI}$ ).

[6] R. Börret, Internal presentation - Fabrication workshop Carl Zeiss, 2001.

[7] H.-P. Kurz, "Ultrapräzises Fräsen von Oberflächen in optischer Qualität (Ultra precision milling of surfaces in optical quality)", in Studiengang Optoelektronik 2006, (Aalen University, Aalen, 2006) in German.

[8] NovoPlan GmbH. Nickel plating. (27.07.2011), Available from: http: //www.novoplan.com.

[9] J. Dong, et al., "Method for micromachining metallic materials", Unknown Journal or Book 2006.

[10] M. P. Mandina, "Design, Fabrication, and Testing; Sources and Detectors; Radiometry and Photometry", in Handbook of Optics, M. Bass, Editor, (2009).

[11] E. D. Doyle, and R.L. Aghan, "Mechanism of metal removal in the polishing and fine grinding of hard metals", Metall. Mater. Trans. B 6(1), 143-147 (1975).

[12] S.P. Rockwell, "Hardness Testing Machine", in unknown book, U.S.P. Office, Editor (1924).

[13] DIN EN ISO 6508-1, Metallische Werkstoffe - Härteprüfung nach Rockwell, in Teil1: Prüfverfahren (Skalen $A, B, C, D, E, F, G, H, K, N$, T) (ISO 6508-1:2005) 2006 in German.

[14] W. D. Callister, Hardness and other mechanical property considerations, in Fundamentals of materials science and engineering (John Wiley a Sons, Inc, 2001)

[15] S. Rebeggiani, et al., "Towards robust polishing strategies for moulds and dies", in Proceedings of the $3 r d$ Swedish Production Symposium, (Göteborg, Sweden, Swedish Production Academy, 2-3 December 2009).

[16] G. Bogatyreva, M. Voloshin, and V. Padalko, "Detonation synthesized nanodiamond powder for the preparation of porous polycrystalline micron powders", Diam. Relat. Mat. 17(3), 213-216 (2008).

[17] V. Y. Dolmatov, "Detonation synthesis ultradispersed diamonds: properties and applications", Russ. Chem. Rev. 70(7), 607-626 (2001).

[18] N. Chkhalov, et al., "Ultradispersed diamond powders of detonation nature for polishing X-ray mirrors", Nucl. Instrum. Meth. A 359(1-2), 155-156 (1995).

[19] P. Comley, et al., "A High Material Removal Rate Grinding Process for the Production of Automotive Crankshafts", CIRP Ann. - Manuf. Techn. 55(1), 347-350 (2006).

[20] F. W. Preston, "The Theory and Design of Plate Class Polishing Machines", Journal of the society of glass technology XI, (1927).

[21] Carl Zeiss Inc. Industrial Metrology [29.07.12; UPMC ultra CMM]. 